\title{
EVOLUCIÓN DEMOGRÁFICA DE PENÁGUILA. SIGLOS XVI AL XX
}

\author{
Ángel Beneito Lloris
}

Las áreas montañosas de la provincia de Alicante y en especial las de la comarca alcoyana a lo largo de este siglo han visto perder gran cantidad de su población hasta el punto de convertirse en sectores demográficos sumamente depresivos. Los municipios de ésta eran, casi en su totalidad, núcleos moriscos que habían visto, en el mejor de los casos, reducir considerablemente sus efectivos tras la expulsión, o despoblados, habían sufrido nueva repoblación.

Penáguila, por las características concurrentes en ella, era una localidad idónea para estudiar su evolución. Sus Quinque Libri, permanecen intactos con documentación desde 1570 hasta la actualidad; sólo se observan algunas omisiones en los libros de desposados y las defunciones únicamente se interrumpen entre los años 1764-75.

Otra causa fundamental es que la localidad había sido de realengo por lo que no había sufrido directamente la expulsión de sus vecinos, así y todo participaba de las mismas características demográficas que las localidades circundantes directamente afectadas por la expulsión: profunda depresión en el siglo XVII, ligera reactivación hasta finales del siglo XIX y sistemático despoblamiento hasta nuestras fechas.

$\mathrm{Si}$ aceptamos como válidas las cifras que proporcionan los impuestos del morabatí de 1505 y 1536, la población durante estos años no había experimentado crecimiento alguno, y si comparamos el censo de 1510 con el Jerónimo de Muñoz, ésta seguiría estancada hacia la década de los 60.

Si la localidad participó del aumento demográfico que experimentó el res- 


\section{CUADRO I $\left({ }^{1}\right)$}

\begin{tabular}{|c|c|c|c|}
\hline Años & Fuegos & Casas & \\
\hline 1505 & 160 & & Impuesto morabatí \\
\hline 1510 & & 174 & Censo Cortes de Monzón \\
\hline 1511 & 156 & & Impuesto morabatí \\
\hline 1523 & 136 & & Ibídem \\
\hline 1528 & 162 & & Censo Maridatge i Coronatge \\
\hline 1529 & 151 & & Impuesto morabatí \\
\hline 1535 & 166 & & Ibídem \\
\hline $1565-72$ & & 174 & Censo Jerónimo Muñoz \\
\hline 1609 & & 200 & Recuento Caracena \\
\hline
\end{tabular}

to de la población valenciana en la segunda mitad del siglo $\mathrm{XVI}^{2}$, es un hecho que no podemos afirmar con seguridad al presentar nuestras dudas el censo de Jerónimo de Muñoz. Si hipotéticamente trabajamos con él, la tasa de crecimiento entre éste y el censo de 1609 sería de 0,40\% para un período aproximado de 40 años, cifra de crecimiento lejana al 1,07\% que experimentó para este mismo período el resto de la población valenciana ${ }^{3}$.

Los totales anuales de nacimientos registrados, sólo experimentan una ligera evolución ascendente durante el corto período comprendido entre los años 1590-98. Ya el año 1599 iniciará el proceso de una inflexión descendente que se adentrará en el siglo XVII, no volviéndose a alcanzar el máximo de 1598 «36 nacimientos» hasta el último tercio del siglo mencionado.

Esta curva descendente iniciada en 1599 continúa su inflexión durante los primeros años del siglo XVII y en 1610-11, los nacimientos y la nupcialidad caen en picado mientras que la mortalidad se dispara alcanzando la punta más elevada de toda la centuria. Es más que probable que las consecuencias de estos desajustes encuentren su origen en la expulsión morisca. Esta debió perjudicar tanto su demografía como su economía. De una parte debió sufrir un descenso poblacional motivado por la emigración de cristianos viejos hacia tierras dejadas por los moriscos${ }^{4}$. Por otra parte, Penáguila junto con Mun-

$1 \quad 1505,1510,1511,1523,1538,1529$, y 1535 en GARCÍA CÁRCEL, R.: El Censo de 1510 y la población valenciana de la primera mitad del siglo XVI. «Cuadernos de Geografía» n. ${ }^{\circ} 18$, Valencia 1976. 1565-72, 1609 en HALPERIN DONGHI, T.: «Un conflicto nacional. Moriscos y cristianos viejos en Valencia». Institució Alfons el Magnànim. Valencia.

2 PÉREZ PUCHAL, P.: «Geografía de la población valenciana». L’Estel, Valencia. 1978. p. 26.

3 Ibídem.

4 Miguel Botilla y sus hijos, al igual que Nofre Vedeca y Cristóbal Bernabeu abandonarán Penáguila para ir a repoblar Sagra y Sanet, A.G.V., Manaments i Empares, 1620, libro 5, mano 46. ff. 31-42 (ap. Gual Camarena, Cartas pueblas). Citado por Halperin Donghi en Un conflicto nacional..., p. 269. 
viedro eran dos villas reales que más terratenientes moriscos tenían, según una estimación hecha por los bayles de las villas reales de Valencia ${ }^{5}$. Gran cantidad de tierras de Penáguila estaban en manos de los moriscos afincados en los lugares vecinos, casi todos en Benilloba, y su expulsión debió colapsar gran parte de la producción agrícola.

Esta fuerte recesión, acusada ya en 1610, llevará a esta década a registrar los valores mínimos de nacimientos y las máximas mortalidades (ver cuadro II), constante que si bien atenuada, continuará patente durante los años 20, convirtiendo este período en el más depresivo del siglo.

Hacia el inicio de este ciclo, cabe situar el recuento de 1616 con 183 fuegos $^{6}$, unos 732 habitantes (índice 4). Si lo comparamos con los 200 fuegos del censo de 1609, Penáguila habría sufrido un descenso intercensal de unos 68 habitantes y una tasa de crecimiento de $-1,27 \%$.

En 1630-37, se nota una ligera reactivación demográfica que se verá frenada bruscamente entre 1640-60, posiblemente consecuencia de las epidemias pestíferas de 1647-52, plagas de langosta en 1640-41 y sequías.

\section{CUADRO II}

Penáguila. Medias decenales 1600-1699

\begin{tabular}{ccrl}
\hline Años & $\frac{\text { Bautismos }}{22,0}$ & \multicolumn{2}{c}{$\begin{array}{c}\text { Defunciones } \\
\text { (Sólo adultos) }\end{array}$} \\
\hline $1600-1609$ & 16,2 & 10,1 & \\
$1610-1619$ & 18,2 & 14,0 & \\
$1620-1629$ & 24,6 & 10,8 & \\
$1630-1639$ & 20,7 & 11,4 & \\
$1640-1649$ & 21,9 & 7,4 & (dos años sin contabilizar) \\
$1650-1659$ & 23,3 & 10,2 & \\
$1660-1669$ & 23,4 & 7,9 & (dos años sin contabilizar) \\
$1670-1679$ & 28,2 & 9,4 & \\
$1680-1689$ & 34,9 & 7,8 & \\
$1690-1699$ & & 8,2 & \\
& & &
\end{tabular}

(1) No se han incluido 25 bautismos efectuados a conversos.

Para este período disponemos del recuento ordenado por la Diputación de la Generalitat en $1646^{7}$; éste anota entre Penáguila y Ares del Bosc, 145 ca-

5 A.C.A. Cons. Ar., leg 607. Citado por Halperin Donghi en Un conflicto nacional..., not. 23, p. 91.

6 AZUAR RUIZ, y PLA ALBEROLA.: «Consideraciones acerca del Maridatge i Coronatge de 1616 referente a la zona de Alicante». Revista de Investigación y Ensayo del I.E.A. Excma. Diputación de Alicante.

7 PÉREZ PUCHAL, P.: Op. cit., not. 19, p. 28. 
sas. Si concedemos a Ares un máximo de 16 casas, cifra que ostentaba antes de la expulsión morisca, Penáguila tendría unas 130 casas de vecinos, unos 520 habitantes por lo que en 30 años habría sufrido un descenso intercensal de 212 habitantes y una tasa de crecimiento del $-1,13 \%$.

La década de los 60 inicia una ligera recuperación que se hará patente a partir de los 80 . Las dos últimas décadas del siglo se caracterizan por un marcado incremento natalicio con unos máximos de 44 bautizos en 1649, mientras que la mortalidad en estos años continúa tendiendo a la baja por lo que los saldos vegetativos son sensiblemente positivos. Del Libro de Visitas obtenemos para el año 1694, 172 casas con 648 vecinos de confesión. Según esto se habría producido un incremento intercensal de al menos 128 habitantes entre los 48 años que los separan del censo de 1648 , con una tasa de crecimiento del $0,46 \%$.

Concluyendo, podemos decir que la primera década del siglo XVII inicia una ligera recesión demográfica que se incrementa durante las dos décadas siguientes, consecuencia de un descenso de nacimientos y un aumento de la mortalidad producido por la expulsión morisca y las crisis agrarias. Durante la década de los 30, se produce una ligera recuperación al aumentar los nacimientos y reducirse la mortalidad. Mientras que la década de los 40 sufre nuevas crisis agrarias y epidémicas provocando un nuevo descenso demográfico. Una ligera recuperación se produce a partir de los años 60 patentizándose a partir de los años 80 . Todo esto hace que los saldos vegetativos sean fiablemente positivos a partir de esta última fecha, siendo muy probable que la crisis demográfica sufrida durante las primeras décadas de siglo empiece a enjugarse a partir de los años 60, aunque llegando a finales de siglo sin haberla superado.

\section{CRECIMIENTO POBLACIONAL EN EL SIGLO XVIII}

Es indudable que el comienzo del siglo XVIII fue negativo para la demografía a consecuencia de la Guerra de Sucesión, aunque la mortalidad catastrófica que acusa Penáguila durante los años 1707-1708 (74 y 43 defunciones respectivamente) no podemos atribuirla como consecuencia directa de la guerra (sólo hay constancia de un soldado portugués que muere en el lugar), más bien hace pensar en desórdenes de tipo socio-económico y en las consecuencias de una epidemia producto del hambre y de la llegada de soldados extranjeros que hizo mella en el término de Alcoy ${ }^{8}$.

Si las últimas décadas del siglo XVII habían preparado y potenciado un aumento demográfico, éste sufre una regresión en la primera década del siglo XVIII; la mortalidad aumenta y la natalidad desciende.

8 BERENGUER BARCELÓ, J.: «Historia de Alcoy». Lloréns distribuidor. 1977. Vol I, p. 371. 


\section{CUADRO III}

Penáguila. Medias Decenales 1690-1799

$\begin{array}{lcrc}\frac{\text { Años }}{1690-99} & \text { Nacimientos } & \text { Defunciones } & \text { Nupcias } \\ 1700-09 & 34,9 & 8,2 & 5,7 \\ 1710-19 & 30,0 & 20,8 & 6,9 \\ 1720-29 & 28,4 & 8,2 & 6,6 \\ 1730-39 & 31,8 & 9,1 & 5,7 \\ 1740-49 & 37,2 & 10,7 & 6,9 \\ 1750-59 & 31,5 & 10,5 & 5,8 \\ 1760-69 & 35,1 & 11,9 & 8,1 \\ 1770-79 & 44,9 & 6,5(2) & 7,9 \\ 1780-89 & 45,9 & 17,5(3) & 10,6 \\ 1790-99 & 53,0 & 36,4 & 11,1 \\ \text { (1) Un año sin contabilizar } & 60,1 & 43,2 & 12,6 \\ \text { (2) Cuatro años sin contabilizar } & & \\ \text { (3) Cinco años sin contablizar } & & \end{array}$

Fuente: Archivo Parroquial. Elaboración propia.

El corto período comprendido entre 1730-39, se caracteriza por una ligera reactivación natalicia y matrimonial que pudo quedar frenada por el alza de los precios del trigo durante 1736, 37 y 38, detectada tanto en Valencia como en Penáguila, provocando un descenso de los nacimientos en la década de los 40 , siguiendo la misma tónica de algunos lugares del interior como Polop, Sella y Biar?

La década de los años 50 será de recuperación demográfica. Según la cifra de población proporcionada por la Fábrica de Paños de Alcoy $^{10}$, Penáguila en 1754 tendría un total de 850 habitantes que comparándolos con los 160 vecinos (entre 640 y 720 habitantes) que el Censo de Campoflorido ofrece para $1712^{11}$, la localidad habría acusado un incremento intercensal que oscilaría entre 130 y 210 habitantes, con una tasa de crecimiento comprendida entre 0,39 y $0,67 \%$ y habría superado en esta época la población que ostentaba antes de la expulsión.

Parte de esta recuperación se pudo deber a la ayuda económica que proporcionaba la incipiente industria doméstica del cardado y del hilado a los in-

9 GOZÁlvEZ PÉREZ, V.: «Notas sobre la demografía de la Provincia de Alicante». Cuadernos de Geografía. núm. 11. Valencia. 1972. p. 7.

10 F.P. Censo de población de Alcoy (30-11-1754). Incluido en Acuerdos de la fábrica 1751-1772. Citado por R. Aracil y M. García en «Industrialització al País Valencià: el cas d'Alcoi». Ed. Eliseu Climent, Valencia 1974. pp. 254-255.

11 B.N. Vecindario General de España o Censo de Campo florido. Ms. 2.274, ff. 345-346. 
suficientes ingresos aportados por la agricultura y que se hacía a través de una manufactura dispersa entre las localidades de la comarca y cuyo centro era Alcoy.

Entre 1762-1788, la natalidad inicia una fuerte reactivación. Todos los índices a excepción de 1764-76 y 1774, están por encima de la media de la centuria y cada década supera a la anterior en el alza de los nacimientos. La mortalidad continua elevando su tendencia a medida que nos acercamos al último decenio de la centuria con dos máximos espectaculares, los de 1779 y 1786, con 72 y 79 defunciones, en ambos casos producto de una elevada sobremortalidad infantil provocando que sean éstos los dos únicos años con saldos vegetativos deficitarios. Mientras que la nupcialidad también experimenta una tendencia alcista a medida que nos acercamos al último decenio, por lo que la constante de esta segunda mitad de la centuria será de crecimiento a pesar de la sobremortalidad antes expresada, de la dramática sequía que sufrió la localidad entre $1787-88^{12}$ y de elevación del precio del trigo durante los últimos años de la centuria.

El Censo de Aranda ${ }^{13}$, establece para 1768 una población de 936 habitantes, representando una tasa de crecimiento del $0,69 \%$ respecto 1754 , mientras que el Censo de Floridablanca anotará 1.325 habitantes en $1787^{14}$ lo que supone un incremento intercensal de 389 y una tasa de crecimiento realmente elevada $1,81 \%$.

Entre 1788 y 1799 , la natalidad continúa experimentando un fuerte incremento, siendo 1799 la cota máxima de toda la centuria con 72 nacimientos. Siguiendo esta tendencia alcista, las defunciones también son las más elevadas de la centuria, aunque los saldos vegetativos son positivos a excepción de 1789. Dentro de este ciclo, conocemos los datos proporcionados por Cavanilles ${ }^{15}$ que para Penáguila ofrece 250 vecinos en 1797, unos 1.125 habitantes aplicando el coeficiente 4,5. Según esto sería un decenio regresivo; en diez años se habría obtenido un descenso intercensal de 200 habitantes. Este decenio no experimentó el alza del anterior pero los saldos vegetativos de la década continúan siendo positivos. Pudo haber un cierto estancamiento, pero este descenso sólo es explicable a través de una emigración, fenómeno que no se producirá hasta el siglo XIX.

Según todos los autores, el siglo XVIII fue de un enorme crecimiento en el País Valenciano. Penáguila habría aproximadamente duplicado sus efectivos a lo largo de este siglo (ver cuadro IV) aumento inferior al estipulado por

12 Archivo Parroquial. Llibre de la renda de la Parroquial de la Villa de Penàguila, 1661. f. 728.

13 R.A.H., Censo de Aranda. Arzopispado de Valencia. 9/6. 175 f. 266.

14 CASTELlÓ-TRAVER, J. E.: «El País Valenciano en el Censo de Floridablanca (1787). Institución Alfonso el Magnánimo. Diputación Provincial de Valencia, 1978.

15 CAVANILLES, A. J.: «Observaciones sobre la Historia Natural, Geografía, Agricultura, Población y Frutos del Reyno de Valencia». Madrid 1975-97. Valencia 1972. Indice de los pueblos del Reyno de Valencia, con los vecinos que tenía en 1794 , T. II. 
Burriel para esta zona que lo fija entre los años 1735-68 y con índices próximos al 300\%, mientras que en Penáguila se inicia entre $1760-80$ y sólo se duplica su población. Este aumento se debió al putting-out dependiente de la industria alcoyana que será base importante de su subsistencia y en menor grado a la puesta a punto de algunos regadíos y la extensión de la vid.

Según Cavanilles:

«Los de Penáguila han descuidado por muchos años la agricultura, y apenas hubieran podido subsistir sin las fábricas de Alcoy, que han dado ocupación y subsistencia a gran parte del pueblo; pero de algunos años a esta parte han extendido el cultivo y aumentado el riego.» ${ }^{16}$

\section{CUADRO IV}

Penáguila. Índices y tasas de crecimiento

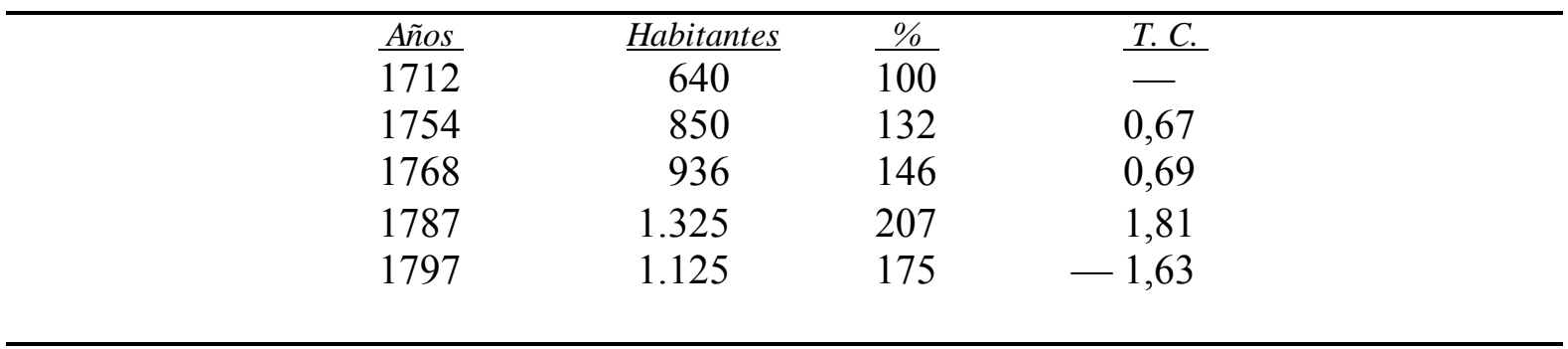

R. Aracil y M. García, al estudiar el hinterland alcoyano sobre datos proporcionados por Cavanilles, han diferenciado tres comarcas dentro de esta región económica. Penáguila, junto con Ares del Bosc, Alcoleja, Beniafer, Benifallim y Benilloba son las componentes de esta tercera comarca, con unos totales de producción muy disminuidos respecto a las otras dos. Penáguila, sólo participa de la producción de esta comarca en granos, vinos y aceite, con una proporción respecto al total comarcal de $47,55 \%, 34,85 \%$ y $43,64 \%$, por lo que el despegue agrícola es muy limitado, aunque la puesta a punto de algunos regadíos y la expansión de la vid habrían favorecido este incremento demográfico de las últimas décadas, unido a una cierta actividad industrial en la que la mano de obra campesina participará de las primeras y más simples etapas del proceso productivo de la industria textil alcoyana, el cardado y el hilado siguiendo un sistema de putting-out que será base importante de su subsistencia.

16 CAVANILlES, A. J.: Op, cit., T. II. p. 198. 


\section{GRÁFICO N. ${ }^{\circ} 1$ \\ PENÁGUILA. EVOLUCIÓN CONJUNTA DE LA NATALIDAD, MORTALIDAD Y NUPCIALIDAD 1700-1799 (Cifras absolutas)}

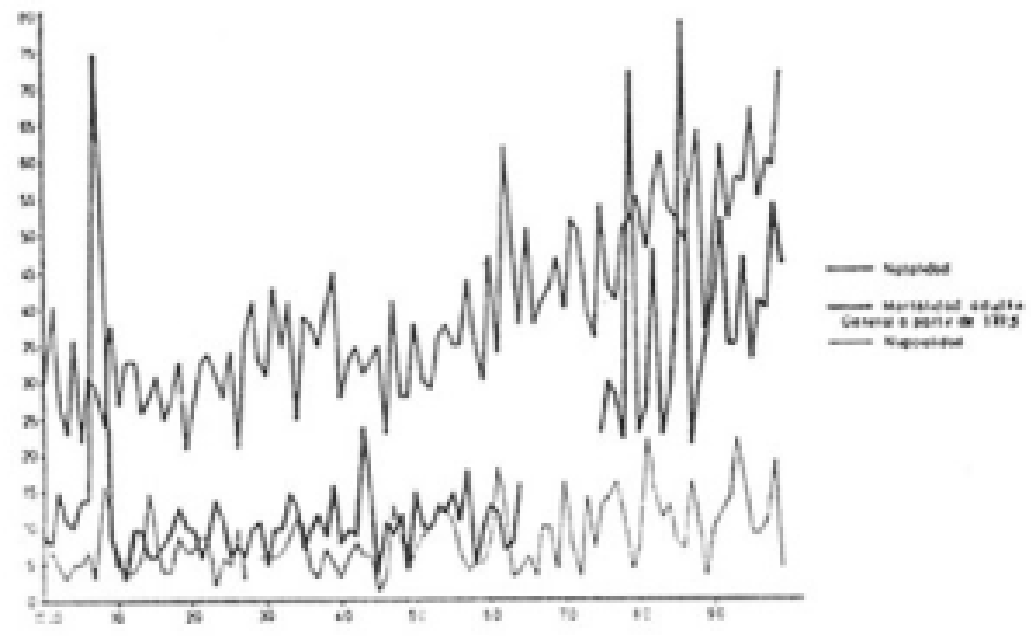

\section{INCREMENTO Y ÉXODO DE LA POBLACIÓN EN LOS SIGLOS XIX Y XX}

El siglo XIX, comienza con una oleada de hambre y un aumento considerable del precio del trigo (por el contrario, parece que la fiebre amarilla no la afectó). Con la invasión francesa, la localidad se vio sometida a impuestos extraordinarios y recaudaciones forzosas ${ }^{17}$.

Los primeros 25 años, se caracterizarán por una natalidad y mortalidad regulares y sostenidas, con escasos altibajos y medias ligeramente superiores a las del total de la centuria, con saldos vegetativos positivos pero bastante débiles, presentando por ello unas características demográficas propias del Antiguo Régimen, altas natalidades contrastadas con fuertes mortalidades que impiden un despegue poblacional.

Los primeros datos que conocemos para este siglo, los proporciona un Padrón Municipal fechado el 5 de mayo de $1807^{18}$ que contabiliza 341 vecinos

17 Archivo Parroquial, Mano de Ordenes y Recibos. Años 1809 y 1810.

18 Archivo Municipal. Expediente de Diligencia del Padrón del Vecindario de esta Villa de Penáguila y lugar de Ares su Anexo. 
y el Libro de Visitas de ese mismo año contabiliza 1.181 personas de confesión, con una población calculada entre 1.200 y 1.400 habitantes, cifra muy similar a la estimada para fines del siglo anterior, por lo que durante la primera década del siglo XIX la población habría permanecido estacionaria.

Entre 1825-49, la natalidad se caracterizará por un marcado descenso respecto al ciclo anterior. Las medias anuales suelen estar o por debajo o muy ajustadas a la media de la centuria. La mortalidad general también seguirá la misma tónica, por lo que los saldos vegetativos de este período aunque débiles continuarán siendo positivos.

\section{CUADRO V}

Penáguila. Medias Decenales 1800-1899

$\begin{array}{cccc}\frac{\text { Años }}{1800-09} & \text { Nacimientos } & \text { Defunciones } & \text { Nupcias } \\ 1810-19 & 61,1 & 45,7 & 143 \\ 1820-29 & 60,5 & 48,4 & 16,2 \\ 1830-39 & 66,2 & 45,8 & 11,6 \\ 1840-49 & 52,6 & 34,9 & 11,8 \\ 1850-59 & 56,3 & 32,9 & 12,1 \\ 1860-69 & 57,3 & 41,8 & 13,1 \\ 1870-79 & 63,6 & 43,7 & 13,3 \\ 1880-89 & 64,4 & 37,3 & 11,7 \\ 1890-99 & 62,9 & 43,4 & 12,2 \\ & 53,7 & 35,7 & 12,0\end{array}$

Fuente: Archivo Parroquial. Elaboración propia.

Tres datos de población conocemos para este ciclo. Sobre 1827, Miñano ${ }^{19}$ proporciona un número de 353 vecinos, con 1.374 habitantes. El Nomenclator de $1834^{20}$ anota 1.283 habitantes incluyendo los de Ares, si adjudicamos a ésta los 143 habitantes que en 1827 apunta Miñano para este lugar, Penáguila tendría en 1834 unos 1.095 habitantes. Para $1847^{21}$, Madoz ofrece unos 1.280 habitantes.

¿Cuál fue la causa que provocó este descenso poblacional entre 1830 y 1850? Como sabemos, Alcoy era a principios de siglo un destacado centro manufacturero que proporcionaba trabajo en el cardado e hilado a una amplia región económica, pero cuando esta capital en expansión necesitó mecanizarse a fin de abaratar los costes, motivó la entrada en crisis de la industria domésti-

19 MIÑANO, SEBASTIÁN de.: «Diccionario Geográfico-Estadístico de España y Portugal». Madrid. 1827. Vol IV. p. 479.

20 MAS Y GIL, L.: «La Provincia de Alicante y sus Antiguos Partidos Judiciales». Alicante C.A.P. 1974.

21 MADOZ, P.: «Diccionario Geográfico-Estadístico-Histórico de España y sus posesiones en ultramar». Madrid 1849. Vol XII. p. 766. 
ca al centralizar todo el proceso manufacturero en Alcoy. A la adquisición de nuevas máquinas textiles entre 1818 y 1823, el campesinado respondió con un movimiento ludita que provocó la desaparición de la industria dispersa y muchos campesinos no podrán subsistir al reducirse sus ingresos, provocando un descenso de nupcialidad y natalidad a la vez que se propicia una incipiente emigración.

A partir de la segunda mitad del siglo XIX hasta 1877, la población empezará a aumentar paulatinamente. Los dos primeros censos oficiales de población ofrecen para 1857 y 1860 unos 1.499 y 1.519 habitantes respectivamente, con una tasa de crecimiento del 0,46\%. El nuevo censo efectuado en 1877 da para la localidad 1.603 habitantes, siendo éste el techo de población más elevado que registra en su historia. La tasa anual de crecimiento sería de $0,32 \%$, con un aumento de población durante estos 17 años de sólo 84 habitantes cuando los saldos vegetativos ofrecen unas cifras positivas de 423 , reflejando esto un movimiento migratorio bastante acusado.

El nuevo período intercensal 1877-1887, experimentará un decrecimiento de 115 habitantes, con una tasa de $-0,74 \%$, aunque los saldos vegetativos ascienden a 120 , reflejando una continuidad en el éxodo emigratorio. La natalidad empieza a sufrir algunos años depresivos con índices inferiores o muy ajustados a la media de la centuria, aunque la tasa continúa siendo elevada 39,65\% , consecuencia de una nupcialidad relativamente alta 9,53\%0. La mortalidad general se elevará considerablemente entre 1885 y 1887 produciendo saldos vegetativos negativos entre esos años, consecuencia de un brote colérico registrado entre 1885 y otro variólico en 1887.

Durante el nuevo período censitario de 1887-97, se volverá a perder población, pasando de 1.488 a 1.344 habitantes siendo la tasa de crecimiento del $-1,02 \%$ reflejando un nuevo aumento en la emigración (máxime cuando los saldos vegetativos son positivos, 203) coincidiendo con el momento de mayor éxodo emigratorio de la provincia.

El escaso período intercensal que hay entre 1897 y 1900, se caracteriza por ser el último que presentará una tasa de crecimiento positiva $0,54 \%$, registrándose en $1900,1.366$ habitantes, 22 más que en 1897.

El excedente poblacional se hará mucho más patente durante la década de 1901-1910 cuyo saldo intercensal será casi nulo, 5 habitantes menos que en 1900, ofreciendo un saldo vegetativo positivo de 223 habitantes para los que la emigración continuará siendo la única solución. La causa de esta elevación en el saldo vegetativo, hay que buscarla en una natalidad elevada, superior al 35\% y una mortalidad que comienza a decrecer.

Durante el segundo decenio 1911-20, Penáguila vuelve a perder población, con un saldo intercensal de -132 habitantes y un saldo vegetativo de 126, por lo que se incrementa el proceso emigratorio, posiblemente reabsorbido por la industria textil alcoyana que experimenta durante esta década un signo expansionista consecuencia de la Primera Guerra Mundial. 


\section{EVOLUCIÓN CONJUNTA DE LA NATALIDAD, MORTALIDAD \\ Y NUPCIALIDAD. 1800-1899 Cif. abs \\ GRÁFICO II}

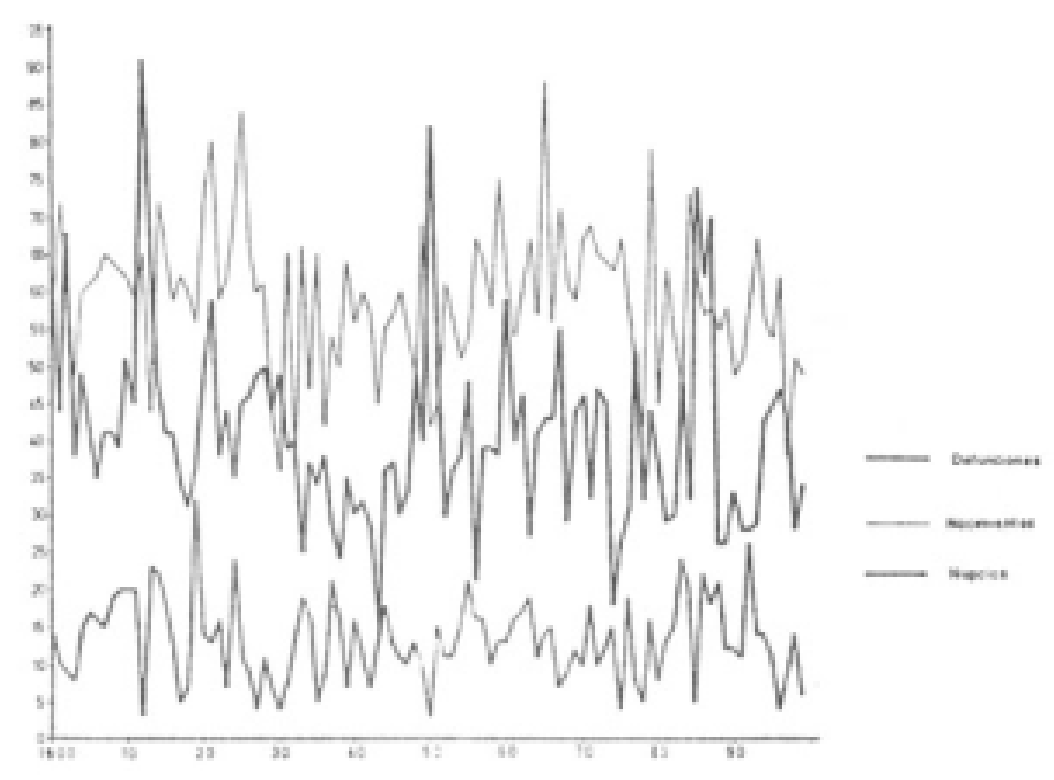

La tasa de crecimiento continuará siendo negativa $-0,95 \%$ durante la década siguiente y su población absoluta descenderá en 112 habitantes. Entre los censos de 1930 (1.117 habitantes) y 1940 (1.103 habitantes) la población absoluta permanece casi estable, a la vez que el saldo vegetativo aunque escaso será positivo -46-, por lo que podemos pensar que durante esta década la emigración quedó casi paralizada. Es muy probable que la Guerra Civil cortara el endémico flujo emigratorio.

Durante los años 40, la tasa de crecimiento continuará descendiendo $-1,59 \%$ y la población absoluta sufre una merma de 163 habitantes.

La población de hecho para 1960, será de 749 habitantes perdiendo 191 respecto al censo de 1950 , ofreciendo una tasa de crecimiento sumamente depresiva $-2,26 \%$, tasa que hubiera podido ser más negativa de no ser por los 86 inmigrantes que recibe la localidad entre $1955 \mathrm{y}$ 1960 , la mayoría de procedencia extraprovincial que viene a suplir las vacantes que deja el campesinado autóctono. El saldo vegetativo de esta década es muy débil 19, consecuencia de un descenso natalicio muy pronunciado.

El ritmo de este proceso continúa durante la década siguiente, perdiendo 
138 habitantes y con unas medias de nacimientos y defunciones que casi se equiparan. Entre el censo de 1970 y el padrón de habitantes de 1975, la población pasa de 611 a 519 habitantes. Durante el segundo quinquenio perderá 96 a tenor de los 423 que anota el nuevo censo de 1980 , número idéntico al estipulado en la rectificación del padrón de 1981, por lo que entre esos doce años perderá 188 habitantes alcanzando la tasa de crecimiento más depresiva $-3,64 \%$ y unos saldos vegetativos que se hacen negativos a partir de 1974; consecuencia de una natalidad que tiende a cero y una mortalidad también muy débil que se nutre de una población sumamente envejecida.

El predominio del secano unidos a las condiciones orográficas y climáticas a la vez que la mitad de sus 5.000 Ha sean de terreno forestal hacen que los rendimientos agrícolas sean bajos, obligando a los escasos excedentes poblacionales a emigrar hacia zonas mejor dotadas. Mientras la población participó en la industria doméstica, se retardó la sangría emigratoria. Cuando este sistema desaparece sustituido por la «fábrica», la industria centralizada absorberá los excedentes poblacionales de las zonas deprimidas de la comarca que verá cómo a partir de la segunda mitad del siglo XIX la emigración se convierte en una constante que llegará hasta nuestros días.

\section{GRÁFICO III \\ EVOLUCIÓN DE LA NATALIDAD Y MORTALIDAD \\ PENÁGUILA. 1900-1982 (Cifras absolutas)}

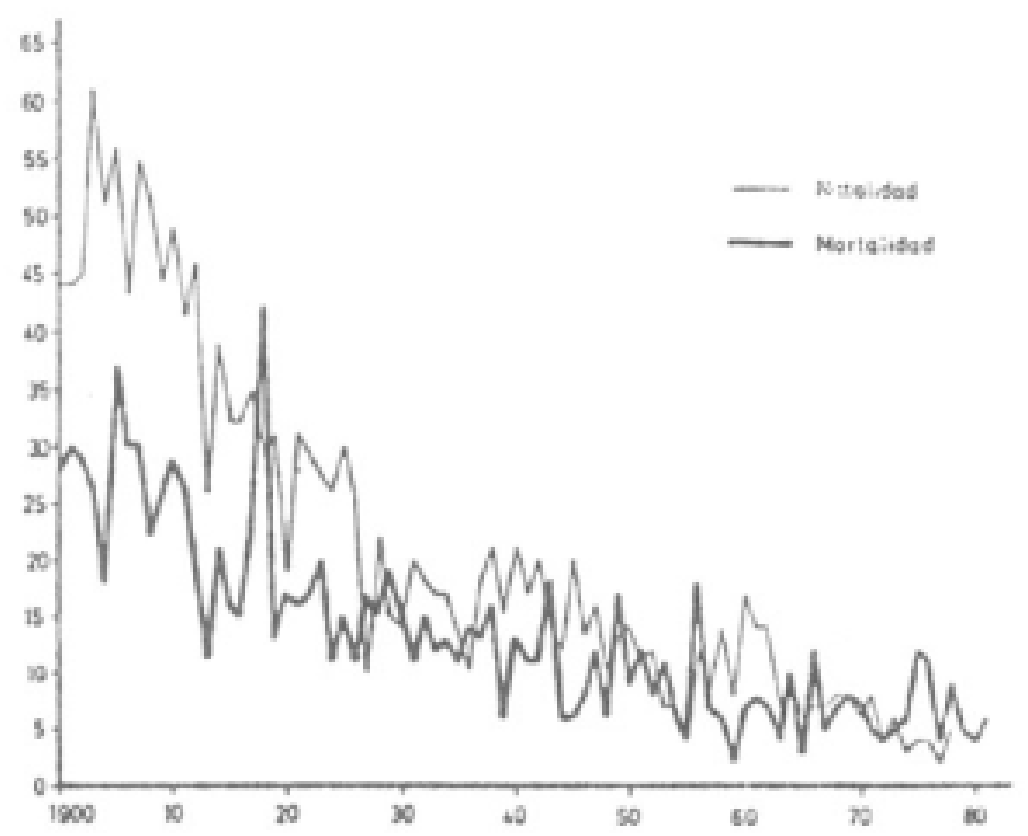


Desde 1877 a 1981, la localidad ha visto perder el 73\% de sus habitantes, llegando en la actualidad a tener una población posiblemente equiparable a la que tuvo en el siglo XVI.

\author{
GRÁFICO N. ${ }^{\circ}$ IV \\ PENÁGUILA. GRÁFICA DE POBLACIÓN. 1576-1980
}

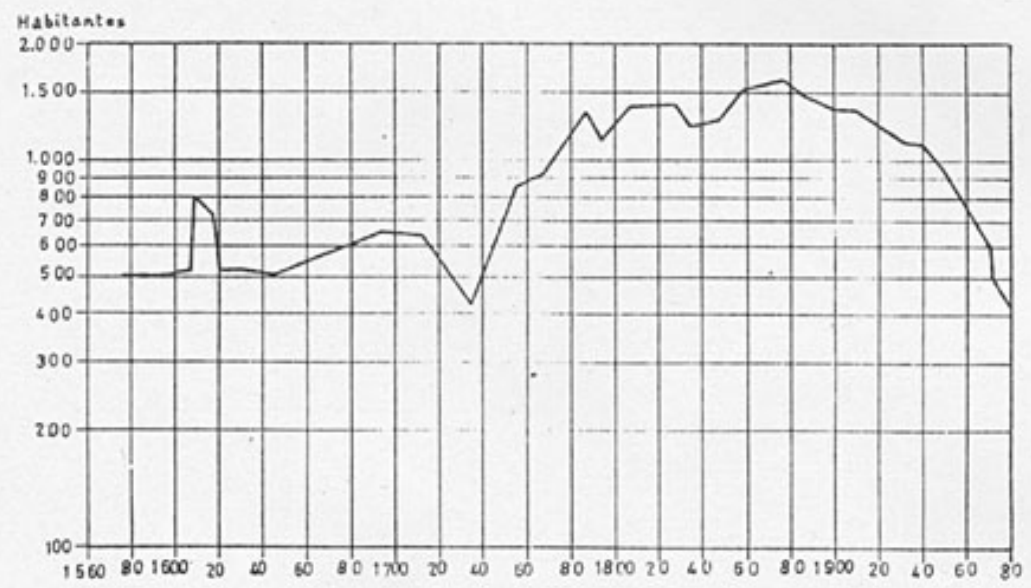

\title{
MOVIMIENTO NATURAL DE LA POBLACIÓN
}

Es indudable que el estudio de las tasas que comportan las tres variables demográficas durante la época preestadística, ofrecerán resultados relativos y criticables al basarse su confección en unos totales de población extraídos a través de un multiplicador $u$ ofrecidos directamente por unos censos y recuentos más o menos fiables. Para evitar mayores irregularidades, obtenemos el coeficiente de cada variable a partir de la media de cada decenio ocupando el año central el dato obtenido en cada censo. 


\section{CUADRO VI}

Penáguila. Evaluación de la población absoluta

\begin{tabular}{|c|c|c|c|}
\hline Fecha & $\begin{array}{l}\text { Número de casas } \\
\quad \text { o vecinos }\end{array}$ & $\begin{array}{l}\text { Número de } \\
\text { habitantes }\end{array}$ & Fuente \\
\hline$\overline{1576}$ & 125 & $(500)$ & Libro de visitas. \\
\hline 1592 & 125 & $(500)$ & Ibídem. \\
\hline 1607 & 130 & $(520)$ & Ibídem. \\
\hline 1609 & 200 & $(800)$ & Censo de Caracena. \\
\hline 1616 & 183 & $(732)$ & Maridatge. \\
\hline 1620 & 130 & $(520)$ & Libro de visitas. \\
\hline 1646 & 145 & $(580)$ & Diputación de la Generalitat (1). \\
\hline 1694 & 172 & $(648)$ & Libro de visitas. \\
\hline 1712 & 160 & $(640)$ & Censo de Campoflorido. \\
\hline 1754 & & 850 & Fábrica de paños. \\
\hline 1768 & & 936 & Censo de Aranda. \\
\hline 1787 & & 1.325 & Censo de Floridablanca. \\
\hline 1794 & & 1.125 & Cavanilles. \\
\hline 1807 & 341 & $(1.364)$ & Padrón Municipal. \\
\hline 1827 & & 1.374 & Miñano. \\
\hline 1834 & & 1.238 & Nomenclator (1). \\
\hline 1847 & & 1.280 & Madoz.. \\
\hline 1857 & & 1.499 & Censo de población de España. \\
\hline 1860 & & 1.519 & Ibídem. \\
\hline 1877 & & 1.603 & $\gg$ \\
\hline 1887 & & 1.488 & $\gg$ \\
\hline 1897 & & 1.344 & $\gg$ \\
\hline 1900 & & 1.366 & $\gg$ \\
\hline 1910 & & 1.361 & $\gg$ \\
\hline 1920 & & 1.229 & $»$ \\
\hline 1930 & & 1.117 & $\gg$ \\
\hline 1940 & & 1.103 & $\gg$ \\
\hline 1950 & & 940 & $\gg$ \\
\hline 1960 & & 749 & $\gg$ \\
\hline 1970 & & 611 & $\gg$ \\
\hline 1975 & & 519 & Padrón municipal de habitantes. \\
\hline 1980 & & 423 & Censo de población de 1-3-1981 \\
\hline 1981 & & 423 & $\begin{array}{l}\text { Rectificación del padrón de } 1981 \\
\text { referido al } 31 \text { de marzo de } 1982 .\end{array}$ \\
\hline
\end{tabular}

Las cifras entre ( ) se han estimado mediante el coeficiente 4.

(1) Incluye la población de Ares del Bosc. 


\section{CUADRO VII}

Penáguila. Índices del movimiento natural de la población. Medias decenales (Tantos por mil)

\begin{tabular}{|c|c|c|c|c|}
\hline Años & $\underline{\text { Natalidad }}$ & $\underline{\text { Mortalidad }}$ & $\frac{\text { Crecimiento }}{\text { Natural }}$ & Nupcialidad \\
\hline $1572-81$ & 35,8 & & & 11,8 \\
\hline $1588-97$ & 46,8 & & & 12,8 \\
\hline $1603-12$ & 44,2 & & & 10,1 \\
\hline $1605-14$ & 27,5 & & & 7,7 \\
\hline $1612-21$ & 24,3 & & & 7,2 \\
\hline $1616-25$ & 36,1 & & & 9,8 \\
\hline $1642-51$ & 37,0 & & & \\
\hline $1690-99$ & 53,8 & & & 8,8 \\
\hline $1708-17$ & 45,6 & & & \\
\hline $1750-59$ & 41,2 & & & 9,5 \\
\hline $1764-73$ & 38,0 & & & \\
\hline $1783-92(1)$ & 40,2 & 33,4 & 6,8 & 7,7 \\
\hline $1790-99$ & 52,5 & 38,7 & 13,8 & 11,2 \\
\hline $1803-12$ & 44,7 & 32,3 & 12,4 & 11,2 \\
\hline $1823-32$ & 42,7 & 32,1 & 10,6 & 7,1 \\
\hline $1830-39$ & 42,4 & 28,1 & 14,3 & 9,5 \\
\hline $1843-52$ & 40,0 & 31,0 & 11,0 & 8,9 \\
\hline $1853-62$ & 40,1 & 25,9 & 14,2 & 9,8 \\
\hline $1856-65$ & 42,1 & 25,8 & 16,3 & 9,5 \\
\hline $1873-82$ & 37,6 & 21,4 & 16,2 & 7,3 \\
\hline $1883-92$ & 38,3 & 28,7 & 9,6 & 11,4 \\
\hline 1893-1902 & 37,9 & 26,4 & 11,5 & 8,1 \\
\hline 1896-1905 & 36,6 & 23,3 & 13,3 & 8,2 \\
\hline $1906-15$ & 31,3 & 16,9 & 14,4 & 7,6 \\
\hline $1916-25$ & 23,5 & 15,3 & 8,2 & 5,7 \\
\hline $1926-35$ & 15,3 & 12,4 & 2,9 & 7,1 \\
\hline $1936-45$ & 15,2 & 10,3 & 4,9 & 8,4 \\
\hline $1946-55$ & 11,3 & 9,8 & 1,5 & 6,8 \\
\hline $1956-65$ & 14,5 & 9,6 & 4,9 & 7,6 \\
\hline $1966-75$ & 9,9 & 11,6 & $-1,7$ & 6,8 \\
\hline $1971-79$ & 7,7 & 12,5 & $-4,8$ & 6,1 \\
\hline 1980 & 4,7 & 9,4 & $-4,7$ & 0,0 \\
\hline
\end{tabular}

(1) A partir de 1775, se incluyen las defunciones de párvulos. 
Los índices elevados de natalidad y nupcialidad que experimenta la población a principios del siglo XVII, quedan frenados después de la expulsión morisca y su reactivación no será efectiva hasta finales de ese siglo en que la tasa de natalidad se mantendrá por encima del $40 \% 0$ hasta 1865. La mortalidad también se mantendrá elevada con tasas superiores al 30\% hasta la segunda mitad del siglo XIX. Igual comportamiento presentará la nupcialidad con índices que oscilarán entre el 8 y el 11\%0.

Si observamos los índices decenales de natalidad, comprobamos que ésta se mantiene por encima del 40\%o desde finales del siglo XVII hasta 1865 . Entre 1873 y 1915 pasarán del 38,3\%0 al 31,3\% y aunque descienden respecto al período anterior continuarán siendo elevados y superiores a las nacional y provincial. Será durante la década siguiente cuando la tasa se colocará por debajo de la media provincial, aunque debemos considerarla relativamente elevada habida cuenta de la escasísima tasa de nupcialidad que registra la década. El descenso paulatino, se agudiza hasta llegar a nuestros días con una tasa del 4,7\% . Sólo la década comprendida entre 1956-65 los elevará ligeramente consecuencia del escaso aporte inmigratorio que recibe la localidad entre esas fechas.

Siguiendo las mismas pautas, la mortalidad más elevada la ostenta la década comprendida entre 1790-99, posiblemente consecuencia de la crisis registrada para fines de esa centuria. Durante la primera mitad del siglo XIX, las tasas se mantienen superiores al 30\%0 (la excepción de 1830-39 se debe a que el total de población estipulado es excesivo al incluirse en el Nomenclator de 1834 la población de Penáguila más la de Ares del Bosc).

Durante la segunda mitad de esa centuria, las tasas experimentan un descenso, situándose por debajo de la media española. La tasa mínima se alcanzará durante 1873-1882 coincidiendo con el momento de mayor número de población registrado en la localidad. Por el contrario, la década siguiente ocupará la tasa de mortalidad más elevada de la época censal consecuencia de la epidemia colérica y brotes sarampinosos y variólicos.

Los picos de sobremortalidad volverán a aparecer en la década siguiente, la última del siglo XIX, en que las tasas anuales se elevan a índices superiores al 30\%o entre 1894 y 1897, pero no impiden que la media decenal descienda ligeramente, descenso que se hará sostenido en las décadas siguientes (sólo se registra un pico de sobremortalidad en 1918, consecuencia de la gripe) presentando una mortalidad a lo largo de las cinco primeras décadas de este siglo inferior a la media nacional, para equipararse a ella entre 1956-65, en que el descenso queda frenado. En estas dos últimas décadas, la mortalidad se eleva considerablemente, con tasas anuales comparables a las de principios de siglo, consecuencia de una población sumamente escasa y envejecida.

Tasas de mortalidad infantil. Tomada como tal, es decir el número de defunciones habidas menores de un año relacionado con el número de nacimientos, se pueden desarrollar a partir de 1838 en que los registros anotan la edad de la defunción. 


\section{CUADRO VIII}

Penáguila. Mortalidad infantil. Medias quinquenales

(Tantos por mil)

\begin{tabular}{cccr}
\hline Años & \multicolumn{1}{c}{ Tasa } & $\frac{\text { Años }}{1910-14}$ & $\frac{1}{128,56}$ \\
\cline { 2 - 3 } $1840-44$ & 96,84 & $1913-19$ & 119,68 \\
$1845-49$ & 131,14 & $1920-24$ & 93,84 \\
$1850-54$ & 145,46 & $1925-29$ & 176,12 \\
$1855-59$ & 101,17 & $1930-34$ & 47,81 \\
$1860-64$ & 109,94 & $1935-39$ & 84,90 \\
$1865-69$ & 131,78 & $1940-44$ & 9,52 \\
$1870-74$ & 113,33 & $1945-49$ & 0,00 \\
$1875-79$ & 120,44 & $1950-54$ & 83,11 \\
$1880-84$ & 141,69 & $1955-59$ & 23,00 \\
$1885-89$ & 113,44 & $1960-64$ & 14,28 \\
$1890-94$ & 175,29 & $1965-69$ & 0,00 \\
$1895-99$ & 171,13 & $1970-74$ & 33,33 \\
$1900-04$ & 110,75 & $1975-79$ & 0,00 \\
$1905-09$ & 160,27 & & \\
\hline
\end{tabular}

Las medias quinquenales, permanecerán altas durante el siglo XIX y las tres primeras décadas de nuestro siglo con puntas de sobremortalidad anuales cercanas y superiores al $200 \%$, puntas que se convierten en norma entre 1890-1897.

Es a partir de 1931 hasta nuestros días cuando los índices anuales pasan a ser nulos para la mayoría de los años, mientras los escasos años que presentan tasas positivas, éstas toman un cariz desorbitado: 1951 con sólo 3 defunciones infantiles ofrece una tasa de $272 \%$, consecuencia de una natalidad totalmente depresiva producto del despoblamiento.

Distribución mensual de las defunciones. Se puede observar a partir de 1775, en que las actas anotan el mes en que acontece el óbito.

Durante el último tercio del siglo XVIII, el máximo de defunciones adultas se sitúa en los meses de diciembre-enero, con un segundo máximo en abril-mayo, mientras que el mes más sano sería el de junio. Las afecciones bronco-pulmonares podrían ser las causantes de las máximas invernales, mientras que los meses primaverales considerados tradicionalmente como meses «sanos» invierten su término durante este período. La mortalidad infantil eleva fuertemente sus valores durante el verano y otoño para descender en invierno y ocupar las cotas más bajas en primavera.

En el siglo XIX, la mortalidad adulta está muy equilibrada a lo largo de todos los meses, elevándose ligeramente en enero, mientras que el mínimo se- 
guirá siendo junio. La infantil, seguirá comportándose de la misma forma, con máximos invernales y mínimos primaverales.

Durante los primeros 40 primeros años de nuestra centuria, las máximas defunciones de adultos se centran en los meses de enero a marzo, mientras que el mínimo lo ocupará julio. Esta clara estacionalidad desaparece entre 1940-81.

Causas más destacadas en las defunciones de adultos. A lo largo del siglo XIX son en primer lugar las afecciones respiratorias seguidas de las especies morbosas (tuberculosis, cólera, difteria, sarampión y fiebres tifoideas) situándose en tercer lugar las del aparato digestivo. Las defunciones infantiles, invierten los términos situando en primer lugar las diagnosticadas como especies morbosas, el segundo lugar lo ocupan las relacionadas con el aparato respiratorio y en tercer lugar las del aparato digestivo.

La nupcialidad. Ya hemos observado que sigue las mismas oscilaciones que la natalidad. Las fuertes tasas se presentan en las últimas décadas del siglo XVI para quedar frenadas al inicio del siglo XVII, volviendo a recuperar sus máximos entre 1790-1812 para equilibrarse entre 1873-1882 en que la tasa descenderá bruscamente fenómeno que globalmente puede estar asociado al aumento emigratorio. La década siguiente tendrá la mayor tasa de nupcialidad de toda la época estadística, coincidiendo con el fuerte aumento de la mortalidad.

El descenso que inicia el siglo XX, llegará al punto más bajo entre 1916-25 coincidiendo con la recuperación industrial alcoyana y la fuerte emigración hacia Francia que sufre nuestra provincia. Los decenios siguientes experimentan una recuperación, más acusada durante la Guerra Civil, para volver a descender finalizada ésta, descenso que quedará frenado entre 1956-65 por el fugaz aporte inmigratorio que registra la localidad en esas fechas, para volver a descender en las últimas décadas a valores extremadamente débiles 1,9\%0 en 1975, 2\%o en 1976, nula en 1980, agravando la situación el que parte de las nupcias realizadas no fijan su residencia en Penáguila y por tanto las tasas quedan sobrevaloradas.

Respecto a la edad de acceso al matrimonio, los libros parroquiales de desposorios anotan la edad de los cónyuges a partir de 1838 .

Durante el siglo XIX, la edad media era de 25,3 años para los varones y 22,5 años para las mujeres. La distribución porcentual nos da unas cifras del $46,8 \%$ de varones y de $78,8 \%$ de mujeres que contraen sus primeras nupcias antes de cumplir 25 años.

Para las cuatro primeras décadas de este siglo, la edad media se retrasa a 27 y 23,9 . Entre 1941-1980, ésta vuelve a ascender a 29,3 y 25,6 años respectivamente. Como puede verse, la edad de acceso al matrimonio siempre ha sido más temprana en las mujeres que en los hombres, aunque ha ido retrasándose en ambos sexos de forma paulatina aunque a partir de la década de los 60 se aprecia un proceso de rejuvenecimiento. 
Respecto al estado de viudedad y su relación con posteriores nupcias, la mayor proporción de éstas se registra entre la segunda mitad del siglo XVII y la primera del XVIII, reflejo de la inestabilidad demográfica de este período.

\section{CUADRO IX}

Relación entre segundas o posteriores nupcias y total de matrimonios

\begin{tabular}{|c|c|c|c|c|c|c|c|c|c|}
\hline \multirow[b]{2}{*}{ Periodo } & \multirow[b]{2}{*}{ Total bodas } & \multirow[b]{2}{*}{$\begin{array}{c}\text { Total } \\
2^{a s} \text { nupcias }\end{array}$} & \multirow[b]{2}{*}{$\%$} & \multicolumn{5}{|c|}{ Contrayentes en segundas nupcias } & \\
\hline & & & & Viudo & $\%$ & $\begin{array}{l}\text { Viudos } \\
\text { ambos }\end{array}$ & $\%$ & & \\
\hline 1594-1631 & 119 & 26 & 13,0 & 17 & 8,5 & 4 & 2,0 & 5 & 2,5 \\
\hline $1650-1699$ & 311 & 62 & 20,0 & 38 & 12,2 & 11 & 3,5 & 13 & 4,3 \\
\hline $1700-1749(1)$ & & 319 & 58 & 18,1 & 25 & 7,8 & 9 & 2,8 & $\begin{array}{l}24 \\
7,5\end{array}$ \\
\hline $1750-1799$ & 503 & 67 & 13,3 & 28 & 5,5 & 10 & 2,0 & 29 & 5,8 \\
\hline $1800-1849$ & 660 & 103 & 15,6 & 48 & 7,3 & 12 & 1,8 & 43 & 6,5 \\
\hline $1850-1899$ & 661 & 100 & 15,1 & 56 & 8,5 & 6 & 0,9 & 38 & 5,7 \\
\hline 1900-1939 & 346 & 35 & 10,1 & 18 & 5,2 & 9 & 2,6 & 8 & 2,3 \\
\hline $1940-1979$ (2) & & 241 & 8 & 3,3 & 3 & 1,2 & 3 & 1,2 & $\begin{array}{r}2 \\
0,8\end{array}$ \\
\hline
\end{tabular}

Los tantos por cien hacen referencia respecto al total de bodas.

(1) No constan los matrimonios de 1728.

(2) Desde 1950 a 1964 no consta la viudedad en el formulario del Registro Civil.

Fuente: Archivo Parroquial y Registro Civil. Elaboración propia.

Es interesante destacar cómo la constante fundamental estriba en el mayor porcentaje de viudos que contraen nuevas nupcias con solteras. En segundo lugar, las ceremonias se realizan entre viudos mientras que la menor proporción la ocupan las uniones de viudas con solteros.

En la elección de las distintas épocas del año para contraer matrimonio, pueden intervenir diferentes factores: religiosos, económicos, profesionales... que condicionan una mayor o menor distribución de las nupcias a lo largo de los diferentes meses.

Entre 1571 y 1699, los meses de mayor número de bodas fueron: enero, septiembre, noviembre y octubre, mientras que diciembre, marzo y junio ocupan los últimos lugares. La Iglesia Católica a través del Concilio de Trento tiene ordenado que las velaciones y bendiciones nupciales no se hagan ni reciban ni en Cuaresma ni Adviento. Estas prescripciones parecen cumplirse ya que los mínimos más absolutos se obtienen en diciembre y marzo, mientras que los de junio pueden estar relacionados con las actividades agrícolas.

En el siglo XVIII, se observan dos máximos, uno en noviembre-diciembre y otro en febrero-marzo, para ir descendiendo hasta llegar a los mínimos de junio, julio y agosto. Según esto, los meses de mayor actividad agrícola continúan ocupando los mínimos, mientras que los meses invernales ofrecen el mayor número de bodas, por lo que las disposiciones sinodales parecen ahora no respetarse. 
El siglo XIX, concentrará los mínimos entre enero y julio aunque abril experimenta una cierta elevación, posiblemente debida al adelanto de las nupcias de algunas parejas ante los meses de mayor actividad. Mientras que los dos últimos meses de año serán los que tengan un mayor número de uniones. Para nuestro siglo, el nulo nivel de industrialización y la total dependencia al sector primario ha propiciado que las condiciones sean básicamente las mismas. Un ligero incremento en las nupcias durante el mes de abril, un descenso brusco en los meses de verano y unos máximos entre septiembre y noviembre.

\section{MOVIMIENTOS MIGRATORIOS}

Es indudable que para conocer el fenómeno demográfico de una localidad hay que analizar los movimientos migratorios que ésta genera ya sea absorbiendo o expulsando población.

A partir de 1857, los totales de población absoluta referidos en los censos y los saldos vegetativos nos proporcionarán unos saldos migratorios que nos ayudarán a comprender el movimiento poblacional de la localidad, a la vez que los diferentes padrones municipales nos confirmarán la procedencia de los inmigrantes.

Durante la época preestadística, los problemas que plantea conocer el movimiento de su población son por ahora insolubles. Los libros parroquiales anotan en el acta matrimonial la procedencia y vecindad de los contrayentes, aunque para los forasteros a veces sólo se inscribe su naturaleza, no pudiendo afirmar si son vecinos del lugar de donde nacieron o de otro, por lo que sólo tomaremos como inmigrantes a aquéllos que queden inscritos como naturales de un lugar y conste que sean vecinos de Penáguila.

También podemos conocer un cierto índice de emigración referido a las mujeres que contraen matrimonio con varones cuya vecindad no sea Penáguila, dejando por supuesto que la mujer abandona la localidad para afincarse en el del varón.

A partir de estos presupuestos, se puede conocer el número de forasteros vecinos de la localidad que contraen nupcias y el de mujeres que dejan la localidad a causa del matrimonio, pero se tendrá una visión parcial de las migraciones, limitada a los que se $\operatorname{casan}^{22}$.

Según esto, Penáguila en el siglo XVII, registró un total de 33 inmigrantes que se afincaron y contrajeron matrimonio en la localidad, 14 varones y 19 mujeres. En 7 casos su procedencia era extraregnícola, Cardenete (Cuenca), Daroca, Pamplona, Toledo, Tudela, un francés y un borgoñón. La emigración femenina contabiliza un total de 32 que casan con vecinos de lugares cercanos a la localidad.

22 BENITO LLORIS, A.: «Penáguila. Estudio demográfico, siglos XVI-XX». Ver Migraciones. Tesis de licenciatura, inédita. Universidad de Alicante. 1984. 
des circundantes, donde se produce una ósmosis entre ellas. Pero estos datos extraídos nos dan una visión limitada que puede ser indicativa para los siglos anteriores pero que no reflejan la magnitud del movimiento migratorio que se produjo en el siglo XIX, ya que a medida que la industria centralizada iba sustituyendo a la doméstica, fue produciéndose una migración rural que si bien pudo ser débil durante la primera mitad del siglo XIX, aumentó de forma considerable durante la segunda a tenor de los saldos migratorios negativos que llegan hasta nuestros días.

Veamos a través del Padrón Municipal de 1965, el aporte inmigratorio que tuvo la localidad. De los 738 empadronados, 248 no han nacido en el municipio, representando el 33,6\% del total de la población.

Las provincias que aportan más índices de inmigración son: Alicante el 43,1\%, Albacete el 19,6\%, Almería 8,9\%, Murcia 8,5\%, Granada 6,9\%, Valencia 4,0\%, Ciudad Real 3,2\% y Jaén $2,8 \%$. Por lo que el principal aporte lo realiza la propia provincia de Alicante y al igual que en siglos anteriores proviene casi en su totalidad de las poblaciones más cercanas. La otra mitad, la inmigración interprovincial está ocupada por provincias cuya proximidad geográfica hizo que ocuparan también los primeros puestos de inmigración para el total provincial de Alicante durante 1961-70.

El último Padrón Municipal, el referido al 1 de marzo de 1981 incluye 92 habitantes que no han nacido en el municipio. Los mayores aportes los proporcionan las provincias de Alicante $54,3 \%$ del total, Almería 22,8\%, Valencia y Jaén 6,5\%, Albacete 3,2\% y Granada el 2,1\%. Como se observa el mayor porcentaje continúa ostentándolo la propia provincia (con unos nutrientes exclusivamente comarcales) aunque en cifras absolutas ha visto descender su número en algo más de la mitad. Los sustanciosos aportes provenientes de Murcia y Albacete registrados en el Padrón de 1965, casi desaparecen en este último.

Por último añadir que la edad media de los inmigrantes es elevada 46,7 años. Parece indudable que las vacantes dejadas por el campesinado autóctono que marchaba hacia zonas en expansión, fueron ocupadas por inmigrantes que posteriormente han utilizado este nuevo asentamiento como plataforma para el paso a la industria.

\section{ESTRUCTURA DE LA POBLACIÓN}

Las pirámides de 1768 (Censo de Aranda) y 1787 (Censo de Floridablanca), quedan encuadradas según su forma gráfica en las de tipo de régimen antiguo, caracterizadas por una ancha base en función de las altas tasas de natalidad, y un descenso rápido hacia la cúspide en base también a las elevadas tasas de mortalidad. Las dos pirámides reflejan una tendencia joven; entre los 0 y 15 primeros años de vida se encuentran en 34,08 y 33,21\% del total de sus respectivas poblaciones. 
Casi un siglo después, la pirámide de población de 1860, continúa presentando unas características afines a las anteriores: forma triangular con ancha base en las edades más tempranas para escalonarse hacia la cúspide. Los porcentajes continúan denotando una estructura poblacional joven, el 47,7\% de la población se encuentra entre los 0 y 20 años. Esta pirámide acusa una muesca que se inicia a los 6 años y se prolonga hasta los 20 , coincidiendo con la crisis económica de los años 50 que provoca las mínimas natalidades y nupcialidades del período a la vez que la mortalidad alcanza la cota máxima de toda la centuria. Por el contrario, el rectángulo se ensancha para el grupo de 21-25 años coincidiendo con la ligera recuperación que acusa la localidad sobre 1840 .

La pirámide de 1965 acusará ya un cambio en su estructura. Los grupos de edades reflejan un descenso porcentual entre los 0 y 20 años y un aumento en las últimas edades. La particularidad fundamental estriba en la fuerte cuña que se aprecia entre los 10-14 años que puede relacionarse con el brusco descenso que experimentan las tasas de natalidad entre 1953-55, mientras que la cuña apreciada en las mujeres entre 20-24 años y los varones entre 25 y 30 años, sólo es explicable a través de una emigración para esas edades.

Siguiendo la constante de envejecimiento que sufre el municipio, los grupos de edades para 1981, acusan unos porcentajes del $21,9 \%$ en el primer grupo, mientras que los mayores de 60 años representan el 33,2\% del total de la población. Consecuencia de ello, el perfil de la gráfica ha pasado en estos años de ser lineal a invertirse. La longitud máxima de los rectángulos la ocupan las edades más avanzadas, estrechándose a medida que descendemos a los 30 años, para volver a ensancharse ligeramente y descender en las edades más inferiores.

\section{GRÁFICO V \\ PENÁGUILA. PIRÁMIDE DE POBLACIÓN 1768. CENSO DE ARANDA}

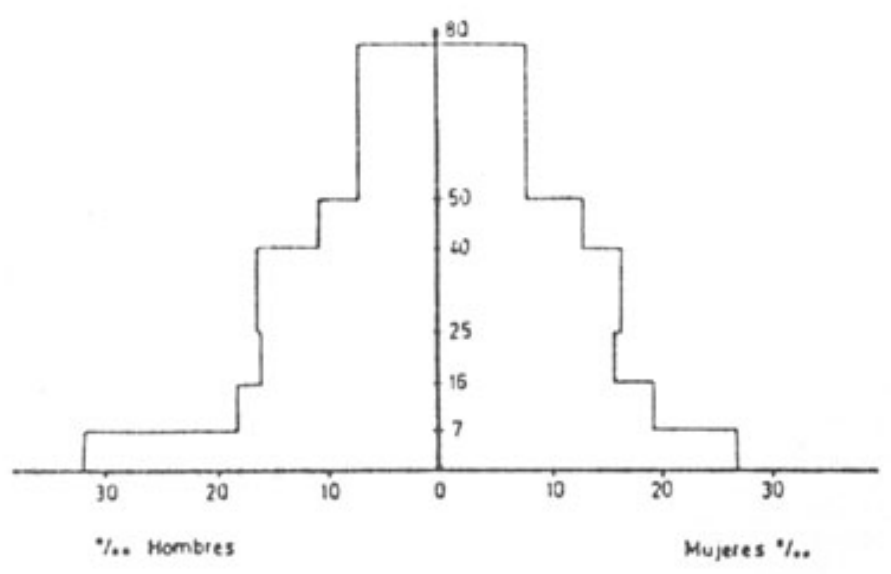


GRÁFICO VI

PENÁGUILA. PIRÁMIDE DE POBLACIÓN 1787.

CENSO DE FLORIDABLANCA

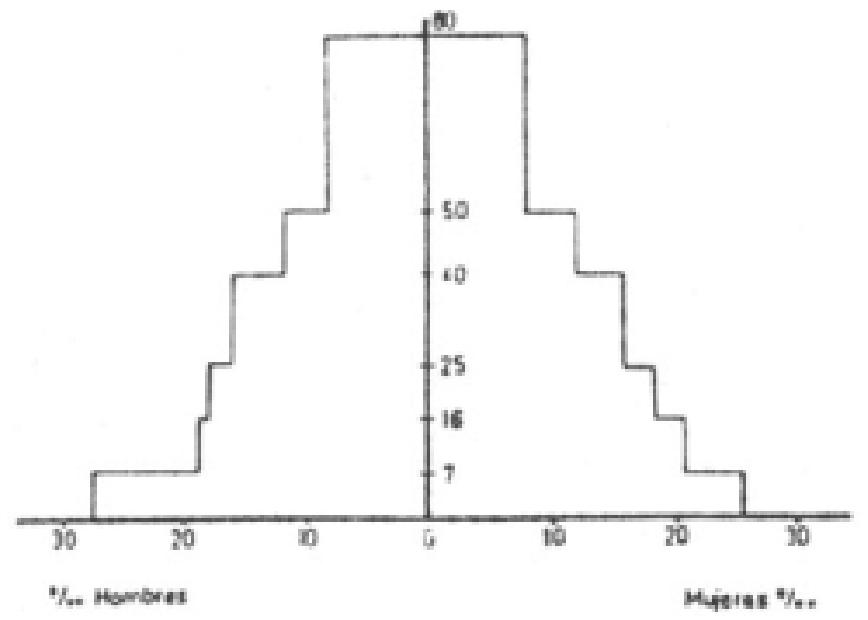

GRÁFICO VII

PENÁGUILA. PIRÁMIDE DE POBLACIÓN 1860.

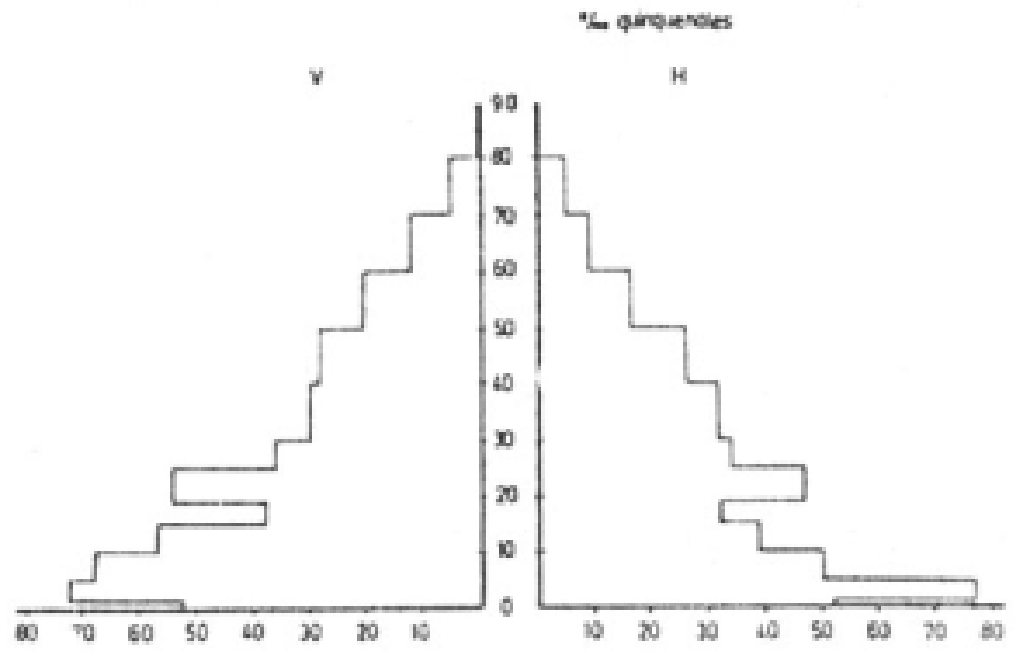


GRÁFICO VIII

PENÁGUILA. PIRÁMIDE DE POBLACIÓN 1965.

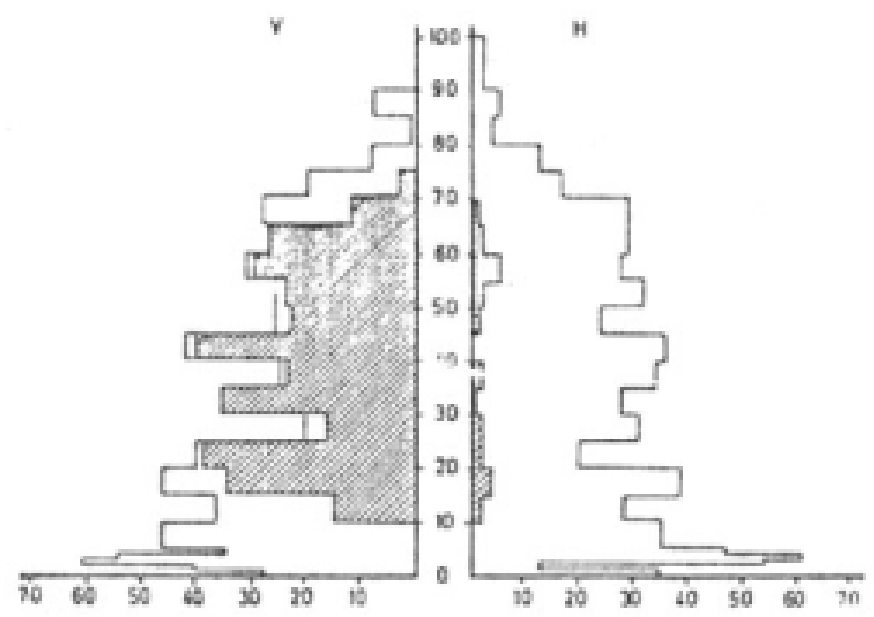

GRÁFICO IX

PENÁGUILA. PIRÁMIDE DE POBLACIÓN 1787.

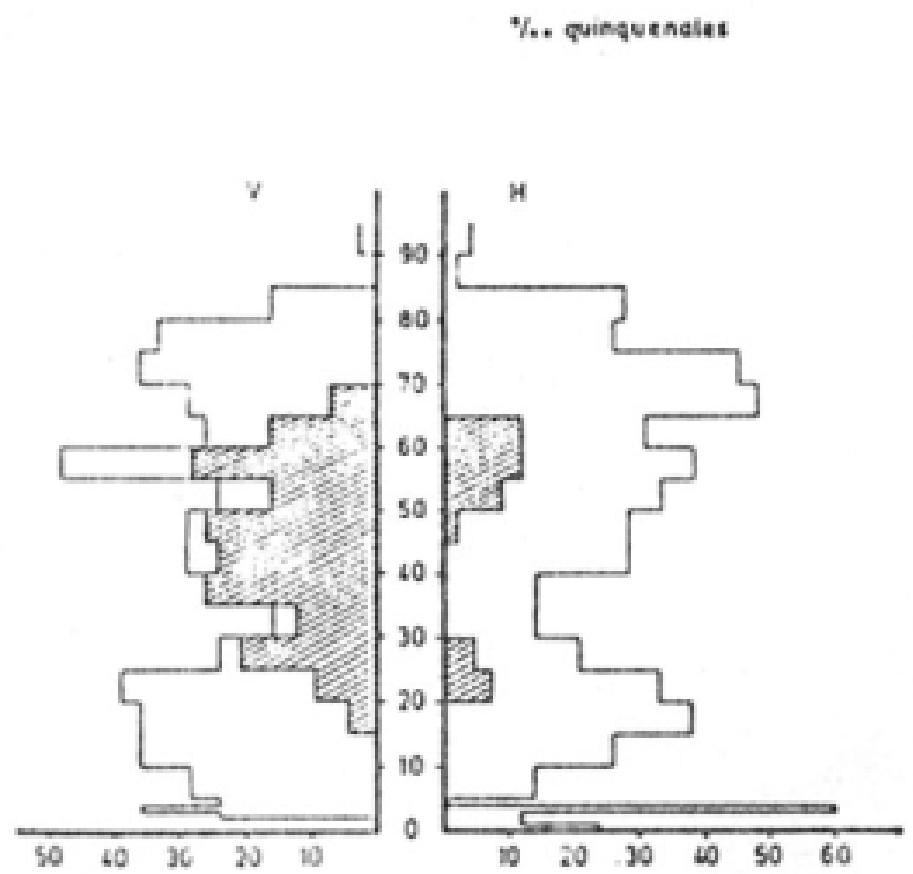


La evolución de la población a través de los grupos de edades, queda reflejada en el cuadro siguiente:

\begin{tabular}{|c|c|c|c|c|c|c|c|c|c|}
\hline \multirow[b]{2}{*}{ Aso } & \multirow{2}{*}{\multicolumn{2}{|c|}{ Queders }} & \multicolumn{4}{|c|}{ 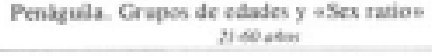 } & \multicolumn{3}{|c|}{ Habey $y$ mb } \\
\hline & & & 8.8. & Tenal & 5 & S.R. & Therf & 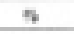 & 5.2. \\
\hline 1857 & 794 & 90,30 & 127,79 & 652 & 43,50 & 93,47 & 93 & 6,20 & 89.90 \\
\hline 1860 & 725 & 47,93 & 115,77 & 696 & 45,92 & 105.38 & 9 & 6.45 & 113.04 \\
\hline 1877 & 912 & 50.65 & 115,56 & 1606 & 41,55 & 90,83 & 125 & T, & 193,10 \\
\hline 1965 & 234 & 31,58 & 115,09 & 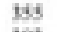 & 45,77 & 164,02 & 145 & 19.75 & 90,79 \\
\hline 1970 & 169 & 27,66 & 105.44 & pos & 49,58 & 106,12 & 139 & 22.75 & 78.95 \\
\hline 1981 & 91 & 21,58 & 116.67 & 187 & 44,35 & 100,11 & 138 & 33.17 & 76.92 \\
\hline
\end{tabular}


En él se observa cómo en el siglo pasado el porcentaje de población juvenil y adulta estaba equilibrado, mientras que la senil no alcanzaba valores superiores al $8 \%$. Durante nuestro siglo, los valores han ido alterándose progresivamente, apreciándose una disminución progresiva y continuada de los porcentajes en las edades juveniles, mientras que las seniles han ido ascendiendo de forma considerable pasando del 19,75\% al 33,17 entre 1965-81.

\section{ESTRUCTURA PROFESIONAL}

El estudio de la población activa se ha efectuado a través de los padrones municipales de 1965, 1970 y 1981. En ellos se constata que entre los dos primeros padrones, la tasa de actividad pasó del 35,2\% al 41,2\%, para descender de forma considerable en este último a $27,9 \%$.

A raíz de los porcentajes de los dos primeros padrones, se podría pensar que hubo un incremento en los puestos de trabajo, pero de hecho el número total de la población activa no varió sino que fue la población absoluta la que descendió en 127 almas, siendo esto lo que elevó el porcentaje de su población activa. Es entre 1970 y 1981 cuando ésta desciende bruscamente, pasando de 252 a 101 ocupados.

\section{CUADRO XII}

Penáguila. Estructura profesional.

\begin{tabular}{|c|c|c|c|c|c|c|}
\hline \multirow[t]{2}{*}{ SECTOR } & \multicolumn{2}{|c|}{1965} & \multicolumn{2}{|c|}{1970} & \multicolumn{2}{|c|}{1981} \\
\hline & Cifras & & Cifras & & Cifras & \\
\hline & absolutas & $\%$ & $\underline{\text { absolutas }}$ & $\%$ & absolutas & $\%$ \\
\hline Primario & 157 & 60,38 & 155 & 61,49 & 70 & 59,32 \\
\hline Secundario & 69 & 26,47 & 53 & 21,01 & 10 & 8,47 \\
\hline Terciario & 34 & 13,06 & 44 & 17,40 & 21 & 17,80 \\
\hline Pobla. activa parada & & & & & 17 & 17,41 \\
\hline Total............. & 260 & 100,00 & 252 & 100,00 & 118 & 100,00 \\
\hline
\end{tabular}

Como se observa, el mayor peso específico lo ostenta tradicionalmente el sector primario, siendo éste el que ha venido ocupando a más de la mitad del total de la población activa, correspondiendo en su totalidad a la agricultura, aunque el último padrón ha visto perder 85 puestos de trabajo, lo que sitúa en tan sólo 70 el número de plazas que genera este sector.

El sector secundario, ha visto descender sus porcentajes entre 1965 a 1981, del 26,4\% al $8,4 \%$, cifra que tomamos como máxima ya que posiblemente la mitad de los homologados en este sector tengan su residencia en la localidad pero no su puesto de trabajo. Entre 1965 y 1970, el mayor peso específico dentro del sector lo ocupó la madera que empleó entre 22 y 24 puestos (el 46,3 y 50\% del total sectorial). A continuación le seguía la construcción y los 
cartonajes. En 1981 todas estas actividades habían desaparecido dejando casi sin efectivos la ocupación en este sector.

El sector terciario, entre 1970 y 1981, se mantuvo en torno al 17\% de la población activa, aunque en cifras absolutas ha descendido a la mitad, aún sin contar que algunos de los anotados tenga su puesto de trabajo fuera de la localidad.

La distribución por sexos en cada sector ha ido cambiando a lo largo de los años. El Padrón de 1965 acusa un nivel de actividad femenina sumamente escaso en los sectores primario y terciario, mientras que el secundario registra un cierto nivel de ocupación a la sombra de unos escasos puestos de trabajo propiciados por los sectores maderero y artes gráficas. A medida que se destruyeron esos puestos, la ocupación femenina en el sector es casi inexistente.

No parece haber ocurrido lo mismo en el sector primario que ha visto aumentar la proporción de mujeres ocupadas en la agricultura. La consecuencia de este aumento puede deberse a una dedicación a tiempo parcial o en algunos casos la adscripción a este sector venga condicionada por las cotizaciones que continúan realizando a la Cámara Agraria a fin de cobrar jubilación, ya que si observamos la composición por edades de la población activa femenina, ésta reduce sus efectivos a dos grupos claramente definidos, uno primero y escaso que se concentra entre los 20 y 30 años y un segundo que iniciándose a los 45 aumenta paulatinamente hasta los 65 años.

El nivel de actividad entre los varones en este último padrón es escaso entre los 15 y 34 años. Los máximos se concentran entre 35 y 60 años con un pico en torno a los 55-59 años.

La distribución de los inactivos a lo largo de estos últimos padrones ha sido siempre bastante elevada, siendo el de 1981 el que alcanza mayores porcentajes, el 67,8\% sobre el total de la población, siendo el grupo de jubilados pensionistas el que ocupa con creces el mayor volumen, representando casi el $30 \%$ del total de la población. 
GRÁFICO X

PENÁGUILA. EVOLUCIÓN DE LA POBLACIÓN ACTIVA.

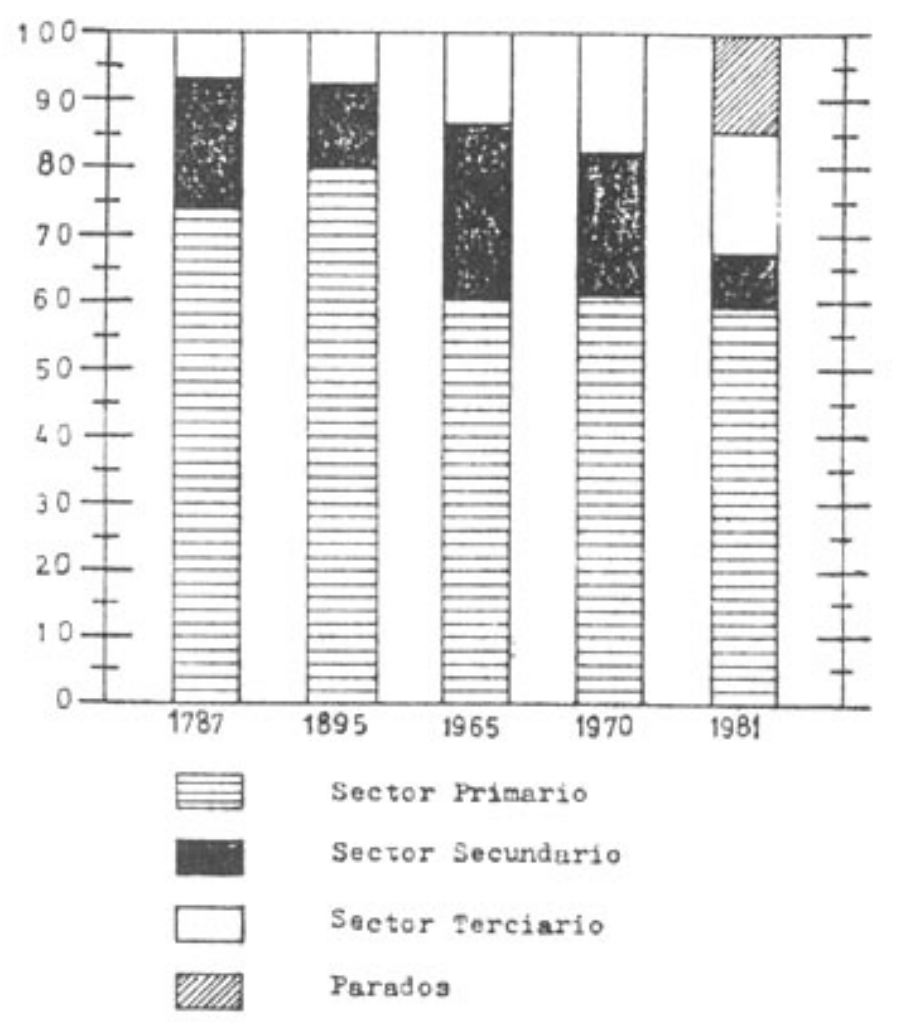

Fuentes: 1787, Censo de Floridablanca 1895, Censo Electoral

1965, 1979 y 1981, Padrón Municipal de Habitantes. 


\section{FUENTES DOCUMENTALES:}

Archivo de la Iglesia Parroquial de la Asunción de Penáguila: Libros de Bautismos, Matrimonios, Defunciones, Visitas Parroquiales, de la renda de la Panochial, Mano de cuentas del Clero, Mano de Ordenes y Recibos, Libros de Limosna Pía, Libros de la Cofradía de Nuestra Señora del Rosario y Cuadernos de Cartas. Archivo Municipal: Registro Civil, Libros Registro de Nacimientos, Defunciones y Matrimonios. Padrones Municipales de 1965, 1970, 1981 y estadillos de Rectificación, años 1971 al 1979. Libro de Monte de Piedad de trigo fundado por Christoval Soler.

Biblioteca Nacional: Vecindario General de España o Censo de Campoflorido.

Real Academia de la Historia: Censo de Aranda. Arzobispado de Valencia.

\section{BIBLIOGRAFÍA}

AGUIRRE SISERA, J. L.: «Terminología Médica 1843-1869». Primer Congreso de Historia del País Valenciano. Vol. IV, Valencia 1976, pp. 449-461.

ALICANTE. Datos y series estadísticas. C.A.A.M., años 1980, 1981 y 1982.

ARACIL MARTÍ, R. GARCÍA BONAFE, M.: «Industrialització al País Valencià: el cas d'Alcoi»». Ed. Eliseu Climent, València, 1974.

ARACIL, R. BERNABÉ, J. M. GARCÍA, M.: «Demografia d'Alcoi: 1860-1936». Primer Congreso de Historia del País Valenciano. Vol. IV, Valencia 1974. pp. 63-79.

-«Les epidèmies colèriques a Alcoi: 1854 i 1885». Ibídem. pp. 375-388.

-«Bateigs, matrimonis i defuncions a Alcoi des del 1843 al 1860». Ibídem. pp. 413-434.

AZUAR RUIZ, R.; PLA ALBEROLA, P. "Consideraciones acerca del Maridatge i Coronatge de 1616 referente a la zona de Alicante». Revista de Investigación y Ensayo del I.E.A. Excma. Diputación de Alicante, pp. 51-57.

BERENGUER BARCELÓ, J.: «El Alcoy del XIX y la Medicina». Imprenta Belguer, Alcoy, 1975.

-«Historia de Alcoy». Lloréns distribuidor, Alcoy, 1977, 3 vols.

BORONAT Y BARRACHINA, P.: «Los moriscos españoles y su expulsión. Estudio histórico crítico». Valencia 1901, 2 vols.

BURRIEL DE ORUETA, E.: «Crecimiento demográfico de las comarcas del País Valenciano en el Siglo XVII». Cuadernos de Geografía, núm. 21, Valencia, 1977, pp. 1-20. 
BUSTELO GARCÍA DEL REAL, F.: «La población española en la segunda mitad del siglo XVII». Moneda y Crédito. núm. 123, Diciembre 1972, Madrid. pp. 53-104.

-«La transformación de vecinos en habitantes. El problema del coeficiente». Estudios Geográficos, núm. 130 Madrid, 1973, pp. 154-164.

-«El Vecindario General de España de 1712 y 1717 o Censo de Campoflorido». (I). Revista Internacional de Sociología, T. XXXII, núms. 7-8, pp. 83-105 C.S.I.C. Madrid 1973. -Ibídem. (y II), T. XXXIII, núms. 11-12, pp. 7-36. Madrid 1974.

-«La població del País Valencià al segle XVII. «Recerques, núm. 5, Barcelona, 1975.

CASEY JAMES.: El Regne de València al segle XVII. «Curiel, Barcelona, 1981.

CASTELLÓ TRAVER, J. E.: «El País Valenciano en el Censo de Floridablanca (1787)». Institución Alfonso el Magnánimo. Diputación Provincial de Valencia, 1978.

CAVANILLES, J. A.: «Observaciones sobre la Historia Natural, Geografía, Agricultura, Población y Frutos del Reyno de Valencia». Madrid, 1795-97. Valencia, Art. Gráficas Soler, 1972, 2 vols.

FIGUERAS PACHECO, F.: «Geografía General del Reino de Valencia». Provincia de Alicante, ap. Carreras Candi, F. Vol V.A. Martín, Barcelona, 1916.

GABINETE SIGMA.: «La economía de Alcoy y Comarca, Aspectos históricos y estructuras actuales. C.A.A.M., 1975.

GARCÍA CÁRCEL, A.: «El censo de 1510 y la población valenciana de la primera mitad del siglo XVI. «Cuadernos de Geografía, núm. 18, Valencia. 1976, pp. 49-66.

GOZÁL VEZ PÉREZ, V.: «Notas sobre la demografía de la Provincia de Alicante». Cuadernos de Geografía, núm. 11, Valencia, 1972 pp. 27-77.

HALPERIN DONGHI, T.: «Un conflicto nacional. Moriscos y cristianos viejos en Valencia». Institució Alfons el Magnànim. Valencia, 1980.

LAPEYRE, H.: «Géographie de l'Espagne morisque». S.E.V.P.E.N. París, 1959.

MADOZ, P.: «Diccionario Geográfico-Estadístico de España y sus posesiones en Ultramar». Madrid, 1849. Vol, XII.

MAS y GIL.: «La provincia de Alicante y sus Antiguos Partidos Judiciales». Alicante, C.A.P., 1974.

MIÑANO, SEBASTIÁN de.: «Diccionario Geográfico-Estadístico de España y Portugal». Madrid, 1826-1829.

NADAL, J.: «La población española (siglos XVI a XX). Esplugues de Llobregat, Ariel, 1976.

PÉREZPUCHAL, P.: «Natalidad, mortalidad y crecimiento demográfico en las comarcas del País Valenciano». Cuadernos de Geografía, núm. 8, Valencia, 1971, pp. 15-33.

-«La población del País Valenciano hasta la época estadística». Cuadernos de Geografía, núm. 10, Valencia, 1972, pp. 1-30.

PROMOCIONES ECONÓMICAS VALENCIANAS, S.A.: «Estudios básicos para la ordenación del territorio de la Comunidad Valenciana. L'Alcoià». Caja de Ahorros de Valencia, 1982.

ROMERO DE SOLÍS, P.: «La población española en los siglos XVII y XIX». Siglo Veintiuno, Madrid, 1973.

SÁNCHEZ ALBORNOZ, N.: «Jalones en la modernización de España». Ariel, Esplugues de Llobregat, 1975.

VICIANA, MARTÍN de.: «Crónica de Valencia». Pub; Sociedad Valenciana de Bibliófilos. Valencia, 1882. 